\title{
Hypoxia with inflammation and reperfusion alters membrane resistance by dynamically regulating voltage-gated potassium channels in hippocampal CA1 neurons
}

\author{
Yoon-Sil Yang ${ }^{1 *}$, Joon Ho Choi ${ }^{1}$ and Jong-Cheol Rah ${ }^{1,2^{*}}$ (1)
}

\begin{abstract}
Hypoxia typically accompanies acute inflammatory responses in patients and animal models. However, a limited number of studies have examined the effect of hypoxia in combination with inflammation (Hypo-Inf) on neural function. We previously reported that neuronal excitability in hippocampal CA1 neurons decreased during hypoxia and greatly rebounded upon reoxygenation. We attributed this altered excitability mainly to the dynamic regulation of hyperpolarization-activated cyclic nucleotide-gated cation (HCN) channels and input resistance. However, the molecular mechanisms underlying input resistance changes by Hypo-Inf and reperfusion remained unclear. In the present study, we found that a change in the density of the delayed rectifier potassium current $\left(I_{D R}\right)$ can explain the input resistance variability. Furthermore, voltage-dependent inactivation of A-type potassium $\left(I_{A}\right)$ channels shifted in the depolarizing direction during Hypo-Inf and reverted to normal upon reperfusion without a significant alteration in the maximum current density. Our results indicate that changes in the input resistance, and consequently excitability, caused by Hypo-Inf and reperfusion are at least partially regulated by the availability and voltage dependence of $K_{v}$ channels. Moreover, these results suggest that selective $K_{v}$ channel modulators can be used as potential neuroprotective drugs to minimize hypoxia- and reperfusion-induced neuronal damage.
\end{abstract}

Keywords: Hypoxia, Inflammation, A-type potassium channel, Delayed rectifier potassium channel, Input resistance

\section{Introduction}

Hypoxia typically accompanies inflammatory responses in patients with stroke or ischemia and in animal models through hypoxia-inducible factor (HIF) and nuclear factor-kB (NF-kB) [1-6]. Interestingly, the inverse situation also occurs. Various inflammatory responses of the brain cause hypoxia by reducing cerebral blood flow [7]. Therefore, to study the effects of hypoxia on pathophysiological conditions more accurately, the combinatorial effect

\footnotetext{
*Correspondence: yus3462@kbri.re.kr; jcrah@kbri.re.kr

1 Korea Brain Research Institute, 61 Cheomdan-ro, Dong-gu, Daegu 41062, South Korea

Full list of author information is available at the end of the article
}

of hypoxia with inflammation (Hypo-Inf) should be considered. However, only a handful of studies have examined the effects of Hypo-Inf on the regulation of neuronal properties and excitability [8,9]. In our previous study, we demonstrated a rapid decrease in neuronal excitability during Hypo-Inf and hyperexcitability upon reoxygenation [9]. We suggest that the hyperexcitability observed upon reperfusion can account for postischemic seizures [10-12], and the molecular mechanisms underlying this change in excitability can provide targets for the prevention of reperfusion injury. We attributed the excitability change mainly to hyperpolarization-activated cyclic nucleotide-gated cation ( $\mathrm{HCN})$ channels and changes in input resistance. Input resistance was decreased by 
Hypo-Inf and increased to a higher level than normal upon reperfusion, suggesting that input resistance can be an additional determinant of neuronal excitability. However, the molecular mechanisms underlying input resistance changes remain to be determined. Such input resistance changes are likely independent of the hyperpolarization-activated current $\left(\mathrm{I}_{h}\right)$ change because $\mathrm{I}_{\mathrm{h}}$ changes in an opposite direction relative to the input resistance. As HCN channels will be partially open constitutively at the resting membrane potential (RMP), the recruitment of $\mathrm{HCN}$ channels would decrease the input resistance $[13,14]$, which is opposite to our observation.

One of the potential candidates for regulating membrane resistance during hypoxia and reperfusion is the voltage-gated potassium $\left(\mathrm{K}_{\mathrm{V}}\right)$ channel because $\mathrm{K}_{\mathrm{V}}$ channels are crucial for maintaining neuronal excitability and are affected by pathological conditions, including stroke and epilepsy [15-18]. In fact, although various studies have suggested the involvement of $\mathrm{K}_{\mathrm{V}}$ channels, it remains controversial how they are affected in these conditions.

Based on their kinetic properties, $K_{V}$ channels can be categorized into A-type potassium $\left(\mathrm{I}_{\mathrm{A}}\right)$ channels, which are transient or rapidly inactivating $\mathrm{K}^{+}$channels, and delayed rectifier potassium $\left(\mathrm{I}_{\mathrm{DR}}\right)$ channels, which show slow or non-inactivating currents. $\mathrm{I}_{\mathrm{A}}$ channels, primarily formed by $\mathrm{K}_{\mathrm{V}} 4$ family channels, regulate input resistance, membrane excitability and synaptic plasticity $[19$, 20]. In corroboration with the idea that $K_{V}$ channels are responsible for input resistance changes with Hypo-Inf and reperfusion, fewer $\mathrm{I}_{\mathrm{A}}$ channels and thereby increased excitability upon posthypoxic reperfusion have been reported [21-23]. On the other hand, other researchers have noted the opposite effect [24-26]. To make the problem even more complex, conflicting results have been reported among studies on the $\mathrm{I}_{\mathrm{A}}$ channel's role in inflammation $[27,28]$. Likewise, the effect of hypoxia and inflammation on $\mathrm{I}_{\mathrm{DR}}$ channels remains controversial [24, 27, 29-36].

The apparent conflicts regarding the involvement of $K_{V}$ channels might be due to the aforementioned mutual inducibility of hypoxia and inflammation in addition to the diverse time points at which hypoxia and reperfusion have occurred in various specimen preparations across experiments. To resolve these conflicts, we investigated the combined effects of hypoxia and inflammation on $\mathrm{K}_{\mathrm{V}}$ channels during hypoxia and reoxygenation. We found that the density of $\mathrm{I}_{\mathrm{DR}}$ channels increased during Hypo-Inf and was reduced to lower than the normal level during reperfusion. Additionally, significantly less inactivation of $\mathrm{I}_{\mathrm{A}}$ channels was observed at the physiological RMP. These results suggest that, at least in part, the altered input resistance may be due to the dynamic regulation of $\mathrm{K}_{\mathrm{V}}$ channels in CA1 pyramidal neurons of the hippocampus.

\section{Materials and methods Slice preparation}

Acute hippocampal slices were prepared from SpragueDawley rats that were between 14 and 21 postnatal days old $(n=10)$. All animal care and treatment protocols were approved by the Animal Care and Use Committee of the Korea Brain Research Institute (KBRI IACUC no. IACUC-18-00028). Rats were decapitated after euthanasia with $\mathrm{CO}_{2}$. The brains were rapidly removed and immersed in an ice-cold cutting solution of the following composition (in $\mathrm{mM}$ ): choline chloride, $110 ; \mathrm{KCl}$, 2.5; $\mathrm{NaHCO}_{3}, 25 ; \mathrm{NaH}_{2} \mathrm{PO}_{4}, 1.25$; glucose, $25 ; \mathrm{CaCl}_{2}$, $0.5 ; \mathrm{MgCl}_{2} \cdot 6 \mathrm{H}_{2} \mathrm{O}, 7$; sodium ascorbic acid, 11.6; and pyruvic acid, 3 . Thereafter, $300-\mu \mathrm{m}$-thick coronal slices were prepared using a vibratome (Leica, Germany). The slices were then incubated for $30 \mathrm{~min}$ at $32{ }^{\circ} \mathrm{C}$ in artificial cerebrospinal fluid (ACSF) containing the following (in $\mathrm{mM}$ ): $\mathrm{NaCl}, 119 ; \mathrm{KCl}, 2.5 ; \mathrm{NaHCO}_{3}, 26 ; \mathrm{NaH}_{2} \mathrm{PO}_{4}$, 1.25; glucose, 20; $\mathrm{CaCl}_{2}, 2 ; \mathrm{MgSO}_{4}, 1$; ascorbic acid, 0.4; and pyruvic acid, 2 . During sectioning, the solutions were oxygenated with $95 \% \mathrm{O}_{2}$ and $5 \% \mathrm{CO}_{2}$.

\section{Electrophysiological recordings}

The slices were transferred to a submerged recording chamber with a continuous flow of ACSF saturated with carbogen $\left(95 \% \mathrm{O}_{2}, 5 \% \mathrm{CO}_{2}\right)$ for whole-cell patchclamp recordings. Slices were visualized using a BX51 WI microscope (Olympus, Japan) through a $40 \times$ waterimmersed objective (numerical aperture 0.8). Patch electrodes with 3-5 $\mathrm{M} \Omega$ tip resistances were prepared using a pipette puller (Sutter Instruments, USA) and filled with internal solution, which was composed of the following (in $\mathrm{mM}$ ): $\mathrm{KCl}, 20$; potassium gluconate, 125; HEPES, 10; $\mathrm{NaCl}$, 4; EGTA, 0.5; ATP, 4; TrisGTP, 0.3; and phosphocreatine, 10 ( $\mathrm{pH} 7.2,290-300 \mathrm{mOsm}$ ). The liquid junction potential (LJP) between the internal solution and ACSF was $14.523 \mathrm{mV}$. The data shown in the present study did not take into account the LJP. The cell capacitances were obtained digitally by using Multiclamp software.

Current-clamp recordings were used to measure the input resistance and action potential (AP) firing rate. Input resistance was determined from the slope of the I-V relationship, which was revealed by plotting the amplitude of the steady-state voltage induced by the hyperpolarizing current injection $(-200 \mathrm{pA}$ to $-50 \mathrm{pA}$, in 50-pA increments), and analyzed using Microsoft Excel. The AP firing rate was obtained by counting the number of APs evoked by 100-pA depolarizing current injection for $600 \mathrm{~ms}$. 
To record the currents of $\mathrm{K}_{\mathrm{V}}$ channels, $0.5 \mu \mathrm{M}$ tetrodotoxin (TTX) was added to the ACSF to block sodium channels, and voltage-clamp recordings were carried out. The density of potassium channels was obtained by dividing the current by the membrane capacitance. $\mathrm{I}_{\mathrm{A}}$ was isolated by subtracting the $\mathrm{I}_{\mathrm{DR}}$ from the total outward potassium current as follows. The total outward currents were elicited by a depolarizing pulse to $+60 \mathrm{mV}$ for $400 \mathrm{~ms}$, following a holding potential at $-60 \mathrm{mV}$. The $\mathrm{I}_{\mathrm{DR}}$ was measured by applying a depolarizing pulse to $+60 \mathrm{mV}$ for $400 \mathrm{~ms}$ after a $-20 \mathrm{mV}$ prepulse for $200 \mathrm{~ms}$ to eliminate $\mathrm{I}_{\mathrm{A}}$. To measure the density of $\mathrm{I}_{\mathrm{DR}}$, the membrane potentials were held at $-20 \mathrm{mV}$ for $200 \mathrm{~ms}$ to remove $\mathrm{I}_{\mathrm{A}}$ and then depolarized to $+80 \mathrm{mV}$ for $400 \mathrm{~ms}$. To determine the inactivation kinetics of $\mathrm{I}_{\mathrm{A}}$, voltagedependent inactivation was assessed by measuring the peak amplitude of current responses by depolarizing to $+60 \mathrm{mV}$ after the prepulse to potentials between -100 and $-20 \mathrm{mV}$ in $10-\mathrm{mV}$ increments. The normalized current was fitted by the Boltzmann equation:

$$
\mathrm{I} / \mathrm{I}_{\max }=1 /\left\{1+\exp \left[\left(\mathrm{V}_{\mathrm{m}}-\mathrm{V}_{\mathrm{h}}\right) / \mathrm{k}\right]\right\},
$$

where $V_{h}$ is the half-maximal membrane potential for inactivation and $\mathrm{k}$ is the slope factor. The activation kinetics of the $\mathrm{I}_{\mathrm{DR}}$ were studied by depolarizing pulses $(-60 \mathrm{mV}$ to $+80 \mathrm{mV}$ in $20-\mathrm{mV}$ increments) following a $-20 \mathrm{mV}$ prepulse to eliminate $\mathrm{I}_{\mathrm{A}}$. The $\mathrm{I}_{\mathrm{DR}}$ was converted into conductance using the formula

$$
\mathrm{G}=\mathrm{I} /\left(\mathrm{V}_{\mathrm{m}}-\mathrm{V}_{\mathrm{rev}}\right) \text {. }
$$

The conductance of $\mathrm{I}_{\mathrm{DR}}$ was normalized and then fitted by a Boltzmann equation.

All electrophysiological recordings were performed at $32{ }^{\circ} \mathrm{C}$, lowpass filtered and digitized at $10 \mathrm{kHz}$ using an Axopatch 700B amplifier (Molecular Devices, Foster City, CA) and Digidata 1550A (Molecular Devices, Foster City, CA).

\section{Hypoxia with inflammation}

Hypoxia was induced by perfusion with ACSF saturated with $8 \% \mathrm{O}_{2}, 5 \% \mathrm{CO}_{2}$, and $87 \% \mathrm{~N}_{2}$, and $10 \mu \mathrm{g} / \mathrm{mL}$ lipopolysaccharide (LPS) was added to ACSF to induce inflammation. Hypo-Inf was induced by perfusion with $10 \mu \mathrm{g} /$ mL LPS-containing ACSF saturated with $8 \% \mathrm{O}_{2}, 5 \% \mathrm{CO}_{2}$, and $87 \% \mathrm{~N}_{2}$. To examine the effect of reoxygenation or wash out of the inflammation, the perfusion solution was changed to normally oxygenated ACSF $\left(95 \% \mathrm{O}_{2}\right.$ and $5 \%$ $\mathrm{CO}_{2}$ ) without LPS.

\section{Data analysis and statistics}

Data acquisition and analysis were performed by using Clampfit 10.4 (Axon Instruments, Foster City, CA) and
IGOR Pro software (Wavemetrics, Lake Oswego, OR). MS Excel (Microsoft, Redmond, WA) software and GraphPad Prism 7.0 (GraphPad Software, San Diego, CA) were used for further data analysis and statistical analysis. All data are presented as the mean \pm standard error (SEM). Statistical significance for comparisons between variables for the same set of neurons, such as control, Hypo-Inf, and reperfusion, was examined using the paired t-test. Otherwise, an unpaired $t$-test was used. Statistical significance was accepted for $\mathrm{p}$ values of $<0.05$ or 0.01 , as indicated.

\section{Results}

\section{Changes in input resistance}

We first tested the input resistance of neurons altered by Hypo-Inf and reperfusion in the presence of TTX. Corroborating our previous study [9], we found that the input resistances were significantly decreased by HypoInf (before: $137.46 \pm 6.18 \mathrm{M} \Omega ; 15 \mathrm{~min}$ after Hypo-Inf: $107.03 \pm 5.51, p<0.01)$, whereas reperfusion significantly increased the input resistance ( $15 \mathrm{~min}$ after reperfusion: $164.45 \pm 13.10 \mathrm{M} \Omega, \mathrm{p}<0.01$; Fig. 1a-c). Of note, the input resistance change coincided with the frequency of APs in response to Hypo-Inf and reoxygenation, suggesting that the input resistance change could contribute to the excitability of the neuron and that voltage-dependent sodium channels were not responsible for this change (Fig. 1c).

\section{Changes in $\mathrm{I}_{\mathrm{A}}$ channels}

To examine whether $\mathrm{I}_{\mathrm{A}}$ channels might participate in changes in the input resistance by Hypo-Inf and/or reoxygenation, we first measured the maximum current density of the $\mathrm{I}_{\mathrm{A}}$ channel. We found that the maximum $\mathrm{I}_{\mathrm{A}}$ density was unchanged during Hypo-Inf and reperfusion (before: $61.6 \pm 5.1 \mathrm{pA} / \mathrm{pF}$; Hypo-Inf: $66.0 \pm 6.46 \mathrm{pA} /$ $\mathrm{pF}$; reperfusion: $56.96 \pm 6.88 \mathrm{pA} / \mathrm{pF}$; Additional file 1: Figure S1), indicating that input resistance during and after Hypo-Inf did not originate from the availability of $\mathrm{I}_{\mathrm{A}}$ channels on the surface of the neurons.

However, the available $\mathrm{I}_{\mathrm{A}}$ density near the RMP can vary depending on the inactivation kinetics of the channel. To determine the inactivation kinetics of $\mathrm{I}_{\mathrm{A}}$ channels, $\mathrm{I}_{\mathrm{A}}$ was elicited by depolarization to $+60 \mathrm{mV}$ after prepulse potentials $(-100 \mathrm{mV}$ to $-20 \mathrm{mV}$ at $10-\mathrm{mV}$ increments). The measured peak currents were normalized with respect to the maximum $\mathrm{I}_{\mathrm{A}}\left(\mathrm{I} / \mathrm{I}_{\max }\right)$ and plotted as a function of the prepulse potential. The normalized current-voltage relationship was fitted by the Boltzmann equation (Fig. 2b). We found that the inactivation curves of $\mathrm{I}_{\mathrm{A}}$ were shifted toward the depolarizing potential by Hypo-Inf without changing the maximum $\mathrm{I}_{\mathrm{A}}$ density and were returned to the control level by reperfusion (Fig. 2b, left). The voltage at half of the maximum $\mathrm{I}_{\mathrm{A}}$ (voltage half or $\mathrm{V}_{\mathrm{h}}$ ) was 


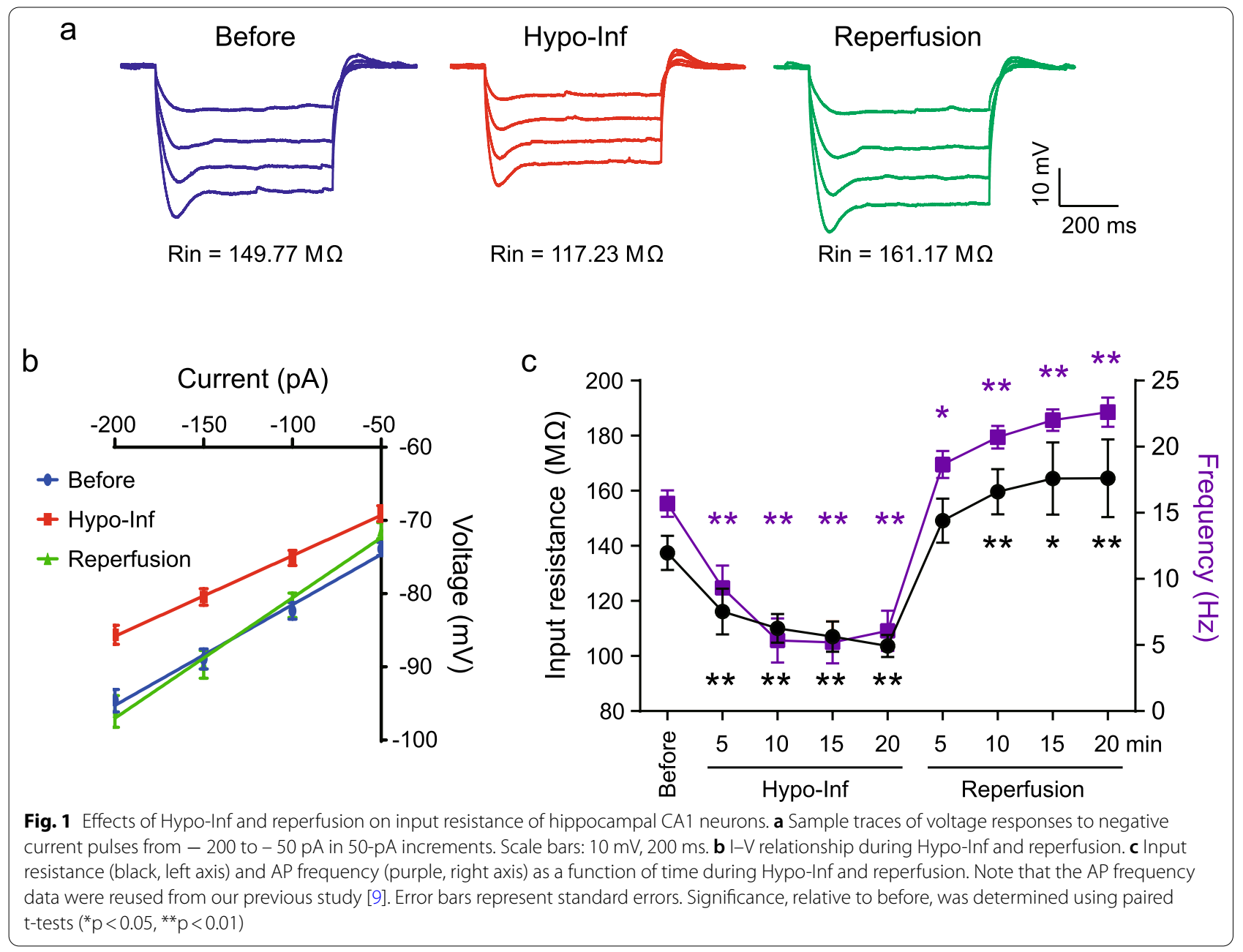

significantly increased from $-54.58 \pm 1.13 \mathrm{mV}$ before to $-48.23 \pm 1.10 \mathrm{mV}$ at $10 \mathrm{~min}$ after Hypo-Inf $(\mathrm{p}<0.01$; Fig. 2c). During reperfusion following Hypo-Inf, the $\mathrm{V}_{\mathrm{h}}$ became comparable to that before $(-54.44 \pm 0.85 \mathrm{mV}$, $\mathrm{p}=0.4851)$. As a result, the $\mathrm{I}_{\mathrm{A}}$ density near the RMPs $(-61.51 \pm 0.97 \mathrm{mV})$ was enhanced during Hypo-Inf (before: $38.88 \pm 3.27 \mathrm{pA} / \mathrm{pF}$; Hypo-Inf: $47.83 \pm 4.31 \mathrm{pA} / \mathrm{pF}$, $\mathrm{p}<0.01)$ but not during reperfusion $(35.28 \pm 3.68 \mathrm{pA} / \mathrm{pF}$, Fig. 2d, left). These results suggested that $\mathrm{I}_{\mathrm{A}}$ channels were involved in downregulating neuronal excitability by shifting the inactivation curve of $\mathrm{I}_{\mathrm{A}}$ channels during Hypo-Inf.

To determine whether the shifted inactivation can be solely explained by either hypoxia or acute inflammatory responses, we also measured the inactivation of $\mathrm{I}_{\mathrm{A}}$ channels under the two separate insults (Fig. 2, middle column). During hypoxia, the inactivation curves of $\mathrm{I}_{\mathrm{A}}$ were shifted in a similar manner as those during HypoInf $\left(\mathrm{V}_{\mathrm{h}}:-54.73 \pm 1.43 \mathrm{mV}\right.$ before and $-47.08 \pm 1.58 \mathrm{mV}$ at $10 \mathrm{~min}$ after the hypoxia insult) and returned to the control level during reperfusion $(-53.36 \pm 3.47 \mathrm{mV})$.
Therefore, the $\mathrm{I}_{\mathrm{A}}$ density near RMPs was altered by hypoxia alone (before hypoxia: $42.67 \pm 3.08 \mathrm{pA} / \mathrm{pF}$; hypoxia: $57.79 \pm 5.43, \mathrm{p}<0.01)$.

Unexpectedly, the inactivation curves of $\mathrm{I}_{\mathrm{A}}$ slightly but significantly shifted toward a depolarizing potential during both the inflammation and washout afterward (Fig. 2, right column; $\mathrm{V}_{\mathrm{h}}$ before: $-55.50 \pm 1.05 \mathrm{mV} ; \mathrm{V}_{\mathrm{h}}$ inflammation: $-52.62 \pm 1.34 \mathrm{mV}, \mathrm{p}<0.01$ ) and stayed depolarized following washout $\left(\mathrm{V}_{\mathrm{h}}-49.94 \pm 1.82 \mathrm{mV}, \mathrm{p}<0.01\right)$. However, the $\mathrm{I}_{\mathrm{A}}$ density near RMP was unchanged by LPS alone.

These results indicated that the $\mathrm{I}_{\mathrm{A}}$ density near RMP was involved in the reduced excitability upon Hypo-Inf, not by changes in the density but by the shifted inactivation kinetics of the channels.

\section{Density of the $I_{D R}$ channels}

We next examined the density of $\mathrm{I}_{\mathrm{DR}}$, the steady-state current of $\mathrm{I}_{\mathrm{DR}}$ normalized by whole-cell capacitance, by hypoxic and/or inflammatory insults. The $\mathrm{I}_{\mathrm{DR}}$ density 
(See figure on next page.)

Fig. 2 Changes in $I_{A}$ channels with hypoxia with or without inflammation. a Example traces of $I_{A}$. Before (blue), insults (red), and reperfusion/ washout (green). Scale bars: 500 pA, 20 ms. b Boltzmann fitted $I_{A}$ inactivation curves. c Averaged voltage half ( $V_{h}$, the dotted line in b); Left: Hypo-Inf; middle: hypoxia; right: inflammation. $\mathbf{d}$ The density of $\mathrm{I}_{\mathrm{A}}$ was measured by depolarization to $+60 \mathrm{mV}$ after a $-60 \mathrm{mV}$ prepulse potential. Error bars represent standard errors. Significance was determined using paired t-tests $\left({ }^{*} p<0.05\right.$ and ${ }^{* *} p<0.01$, compared with each before period)

changed to account for the alteration in input resistance and, thereby, the excitability (Fig. 4). In agreement with the idea that the input resistance was influenced by the $I_{D R}$ density, the $I_{D R}$ density was significantly enhanced during Hypo-Inf (Fig. 3a-c; before: $169.72 \pm 11.55$ pA/ pF; 15 min after Hypo-Inf: $197.59 \pm 14.18$ pA/pF, p < 0.01) and was significantly reduced during reperfusion after Hypo-Inf (15 min after reperfusion: $119.90 \pm 12.80 \mathrm{pA} /$ $\mathrm{pF}, \mathrm{p}<0.01)$.

We previously demonstrated that excitability changes induced during Hypo-Inf and reperfusion were closely replicated by hypoxia alone [9]. Thus, we also examined whether the changes in $I_{D R}$ density may be explained by hypoxia alone. Indeed, an increase in $\mathrm{I}_{\mathrm{DR}}$ density was observed with hypoxia (before: $191.86 \pm 11.08 \mathrm{pA} / \mathrm{pF}$; $5 \mathrm{~min}$ after hypoxia: $240.75 \pm 21.10 \mathrm{pA} / \mathrm{pF}, \mathrm{p}<0.1)$. However, the increased $\mathrm{I}_{\mathrm{DR}}$ density with hypoxia alone was not sustained as long as that with Hypo-Inf (Fig. 3b). The $\mathrm{I}_{\mathrm{DR}}$ density measured at 10,15 , and 20 min after hypoxia without inflammation was similar to that of the control $(200.18 \pm 19.43,189.38 \pm 13.01$, and $170.68 \pm 13.97 \mathrm{pA} /$ $\mathrm{pF} ; \mathrm{p}=0.49,0.88$, and 0.42 , respectively). These results suggested that hypoxia was responsible for the initial increase in $\mathrm{I}_{\mathrm{DR}}$ density, but the combinatorial effect of LPS on proinflammatory responses unexpectedly extended the effects of hypoxia on $\mathrm{I}_{\mathrm{DR}}$ density.

Decreased $I_{D R}$ density by reperfusion after Hypo-Inf could be replicated by reperfusion following hypoxia alone (15 min after reperfusion: $132.04 \pm 6.70 \mathrm{pA} / \mathrm{pF}$, $\mathrm{p}<0.01$ ). In our previous study, we observed that excitability was irreversibly increased by inflammation [9]. Therefore, here, we examined whether $I_{D R}$ density changes could explain this phenomenon. The $\mathrm{I}_{\mathrm{DR}}$ density was slowly reduced and became significant after $20 \mathrm{~min}$ (before: $201.26 \pm 15.12 \mathrm{pA} / \mathrm{pF} ; 20 \mathrm{~min}$ after inflammation: $162.84 \pm 10.69 \mathrm{pA} / \mathrm{pF}, \mathrm{p}<0.05$; Fig. 3d) and remained reduced after washout $(138.89 \pm 7.39, \mathrm{p}<0.01)$. These results suggested that a decrease in $\mathrm{I}_{\mathrm{DR}}$ could be one of the sources of hyperexcitability caused by inflammation.

\section{Changes in the activation kinetics of $I_{D R}$}

The steady-state activation kinetics of $\mathrm{I}_{\mathrm{DR}}$ channels were determined by depolarizing pulses between -60 and $+80 \mathrm{mV}$ in $20-\mathrm{mV}$ increments for $400 \mathrm{~ms}$, following a $-20 \mathrm{mV}$ prepulse for $200 \mathrm{~ms}$ to remove $\mathrm{I}_{\mathrm{A}}$ (Fig. 4a). The conductance was normalized to the maximum value and then fitted with the Boltzmann equation. HypoInf shifted the activation curves of $\mathrm{I}_{\mathrm{DR}}$ in the depolarizing direction $\left(\mathrm{V}_{\mathrm{h}}: 7.81 \pm 1.83 \mathrm{mV}\right.$ before Hypo-Inf and $16.76 \pm 1.78 \mathrm{mV}$ at $15 \mathrm{~min}$ after Hypo-Inf, $\mathrm{p}<0.01$; Fig. $4 \mathrm{c})$ and returned to the control level with reperfusion $\left(\mathrm{V}_{\mathrm{h}}\right.$ : $2.39 \pm 1.78 \mathrm{mV}, \mathrm{p}=0.2801$ at $15 \mathrm{~min},-0.813 \pm 2.28 \mathrm{mV}$, $\mathrm{p}=0.069$ at $20 \mathrm{~min})$. The activation of $\mathrm{I}_{\mathrm{DR}}$ channels was similarly changed by hypoxia alone and reperfusion $\left(\mathrm{V}_{\mathrm{h}}\right.$ : $11.57 \pm 2.45 \mathrm{mV}$ before hypoxia and $18.90 \pm 1.77 \mathrm{mV}$ at 15 min after hypoxia, $\mathrm{p}<0.01 ; \mathrm{V}_{\mathrm{h}}: 6.62 \pm 2.37 \mathrm{mV}$ with reperfusion, $\mathrm{p}=0.2324$, compared with control). The activation kinetics of $\mathrm{I}_{\mathrm{DR}}$ channels were not affected by inflammation $\left(\mathrm{V}_{\mathrm{h}}\right.$ before inflammation: $6.30 \pm 1.10 \mathrm{mV}$; $15 \mathrm{~min}$ after inflammation: $6.06 \pm 1.54 \mathrm{mV} ; 15 \mathrm{~min}$ after reperfusion: $6.25 \pm 1.58 \mathrm{mV}$ ). These results suggested that the increased $I_{D R}$ density could not be attributed to the activation kinetics of the channel, which was different from previous observations $[34,35]$.

\section{Discussion}

In the current study, we explored the contribution of $\mathrm{K}_{\mathrm{V}}$ channels to the previously observed alterations in input resistance and neuronal excitability by combined insults to hypoxia and inflammation and reperfusion. In line with our previous study, we focused our analysis on the effect of hypoxia and inflammation on hippocampal pyramidal neurons. The hippocampus is one of the brain areas most vulnerable to acute ischemic damage. This vulnerability is perhaps due to high energy consumption and restricted blood oxygen saturation [37-40]. Furthermore, ischemic damage in the hippocampus often leads to long-lasting problems, including memory loss and vascular dementia [41-44].

Reportedly, the experimental conditions closely mimic ischemia, including the depletion of ATP evidenced by immediate adenosine receptor-dependent decreases in neurotransmitter release efficiency $[9,45,46]$ and activation of microglial complement receptor 3 (CR3) [8]. CR3 activation in turn produces reactive oxygen species by activating NADPH oxidase, which activates a protein phosphatase critical for long-term synaptic depression [47, 48]. Under these conditions, excitability changes accompanied by $I_{h}$ current and input resistance were observed [9]. 
a

Hypo-Inf

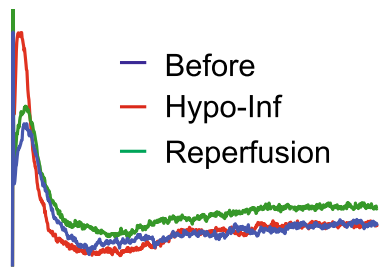

b

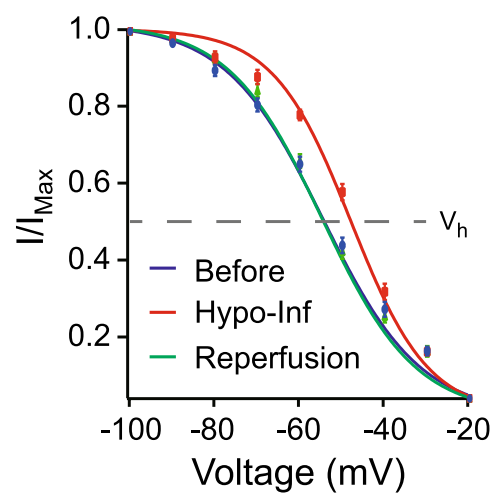

C

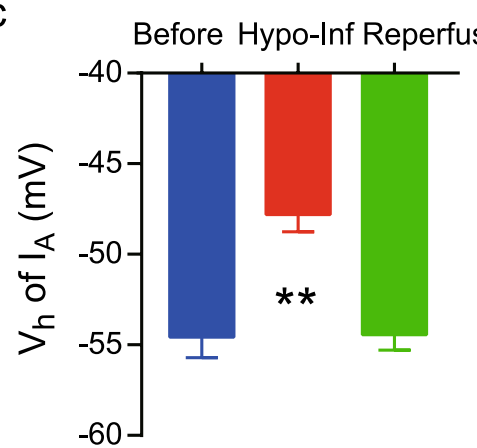

d

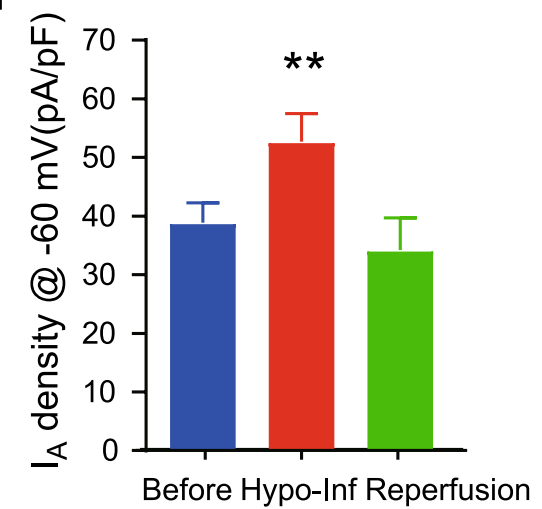

Hypoxia

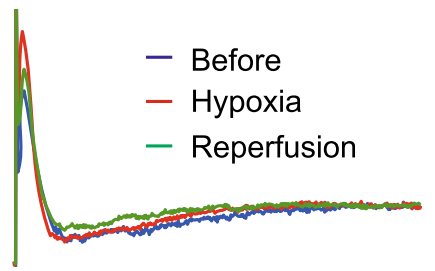

Hypoxia
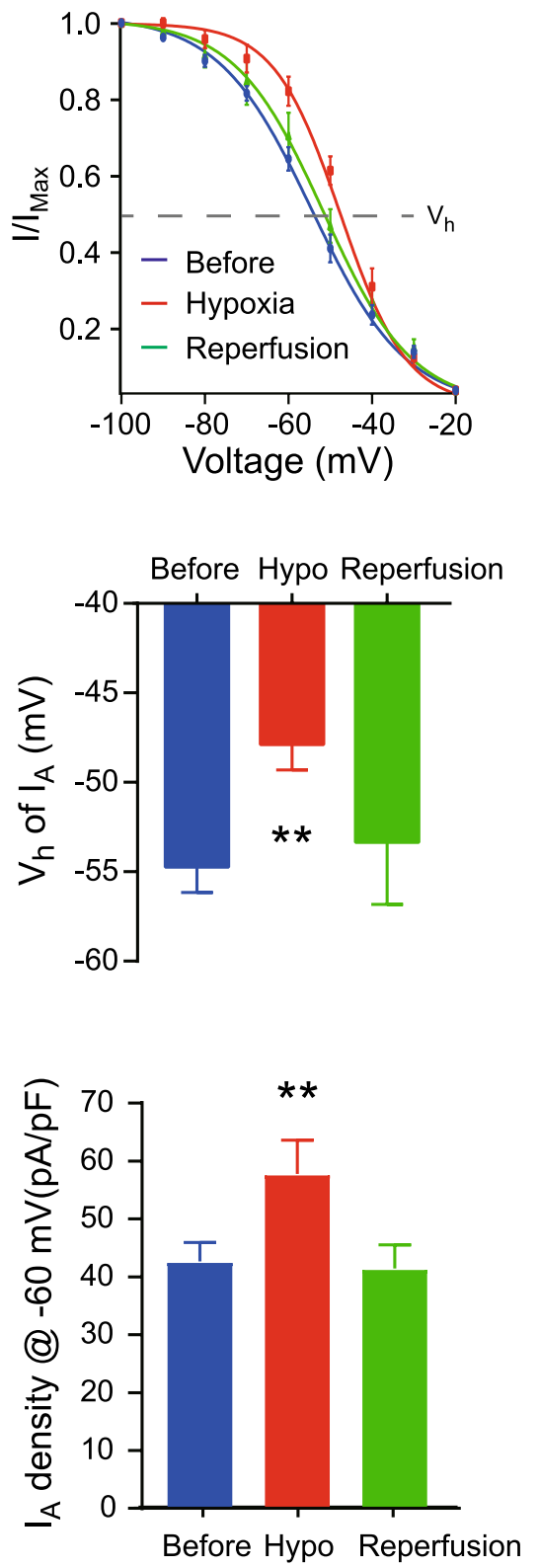

Inflammation
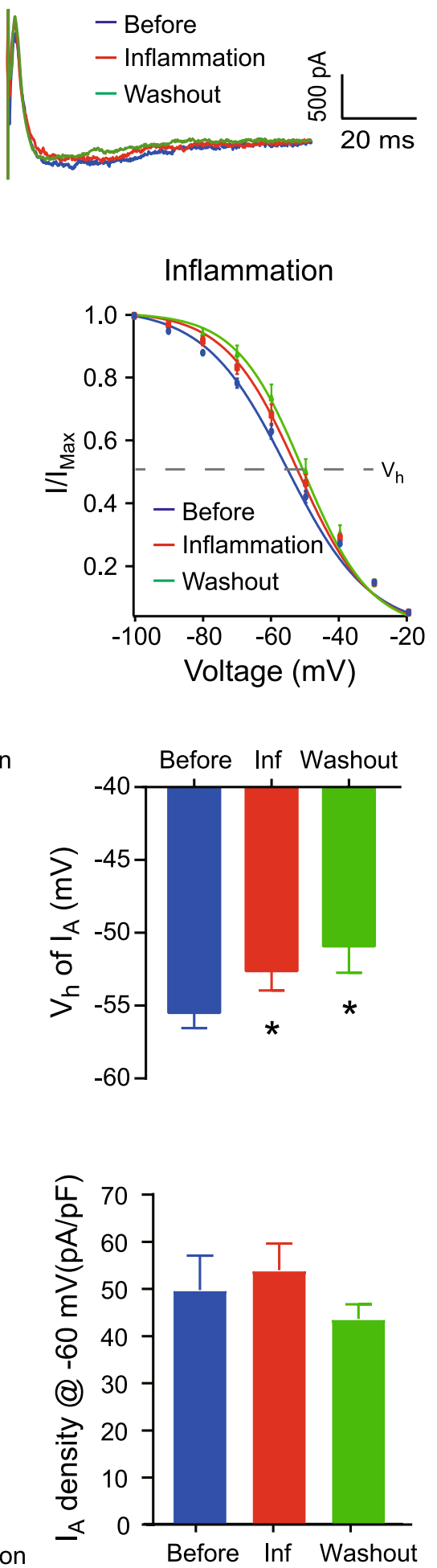

Fig. 2 (See legend on previous page.) 
a<smiles>CCCCCCC</smiles>

Hypo-Inf

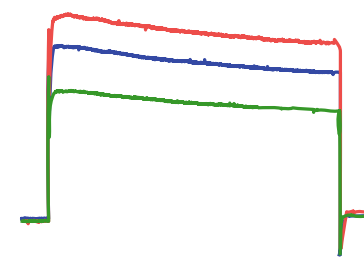

b

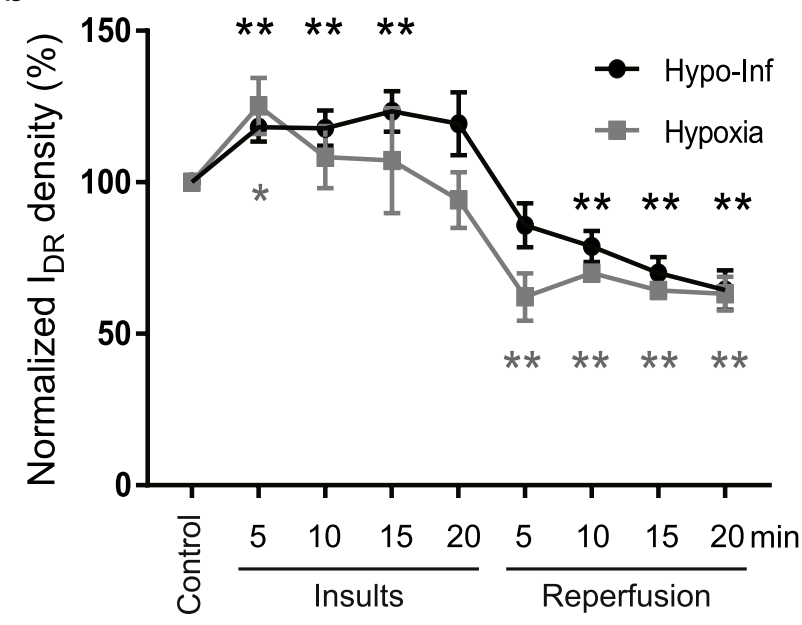

Hypoxia

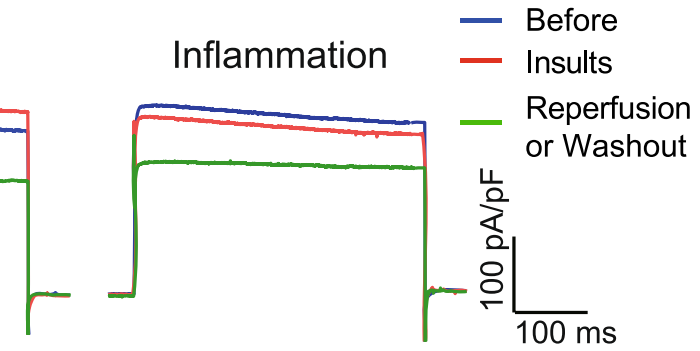

C Before Insults $=$ Reperfusion or Washout

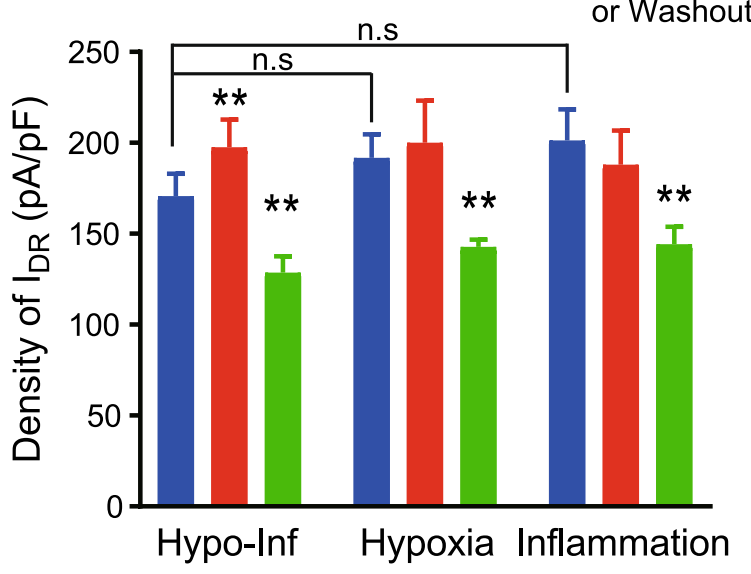

d

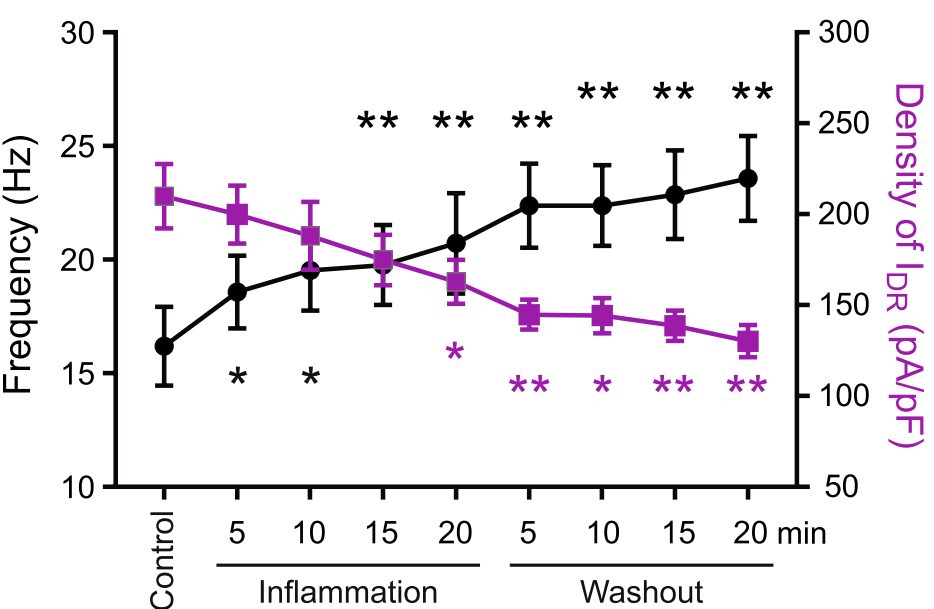

Fig. 3 Changes in $I_{D R}$ density by Hypo-Inf and reperfusion. a Example traces of $I_{D R}$ measured before (control, blue), during (insults, red), and with reperfusion or washout (green); Left: Hypo-Inf; middle: hypoxia; right: inflammation. Scale bars: 100 pA/pF, 50 ms. b The normalized I density with Hypo-Inf (black) or hypoxia alone (gray) and reperfusion. c Comparison of the density of $I_{D R}$ following different insults: before (blue), insults (red), and reperfusion (green). $\mathbf{d}$ The change in firing frequency in response to 100-pA current injection (left axis and black circles) and $\mathrm{I}_{\mathrm{DR}}$ density (right axis and gray squares) with inflammation and washout $\left({ }^{*} p<0.05\right.$ and ${ }^{* *} p<0.01$, compared with each before period) 
a

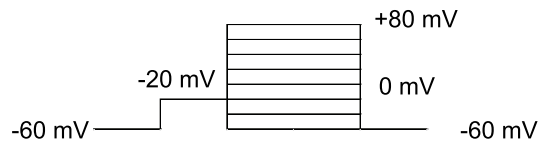

Before

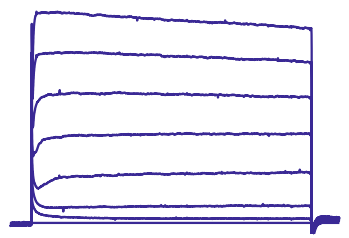

b

Hypo-Inf

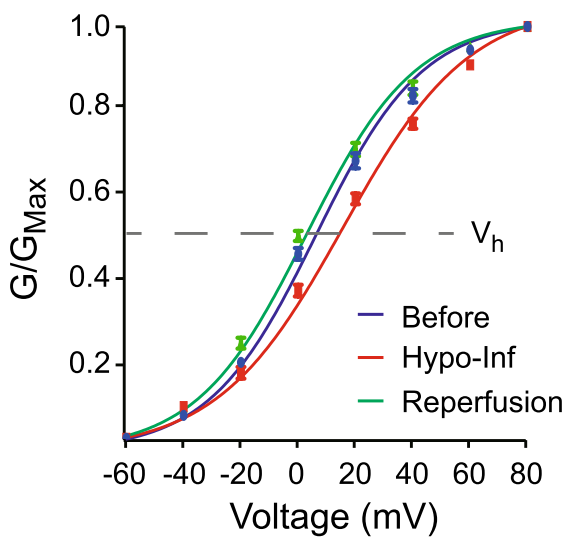

Hypo-Inf

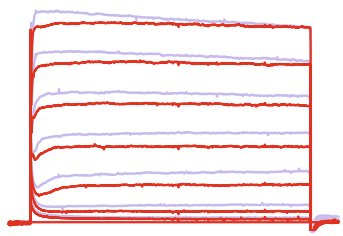

Reperfusion

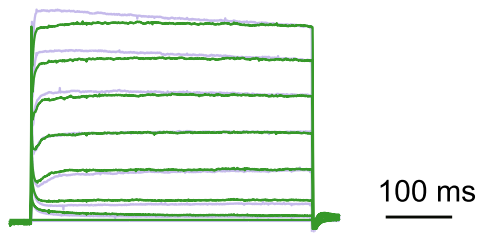

Hypoxia

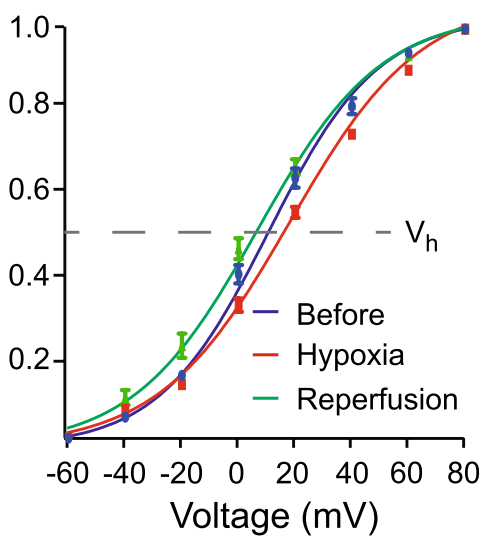

Inflammation

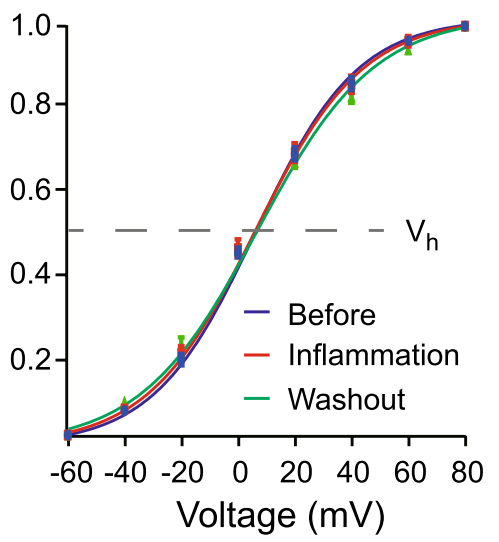

C

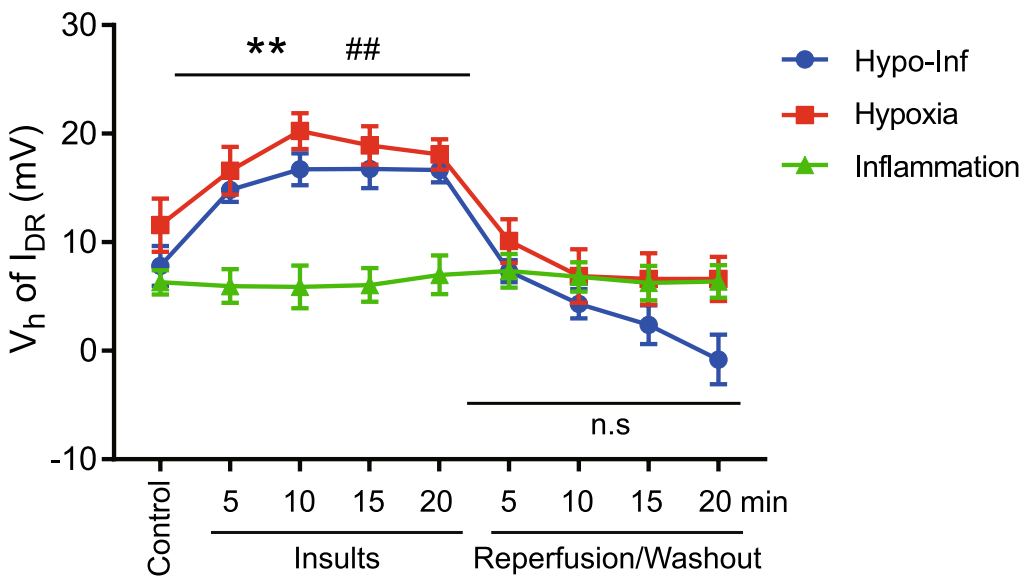

Fig. 4 Activation kinetics of $I_{D R}$ with Hypo-Inf, hypoxia, and inflammation. a Example traces of normalized I $I_{D R}$. Each trace shows control (blue), Hypo-Inf (red), and reperfusion (green). Scale bars: 100 ms. b Fitted Boltzmann curves of gating kinetics of I hypoxia; right: inflammation. c Averaged values of voltage half $\left(V_{h}\right.$, the dotted line in $\left.\mathbf{b}\right)$ over the course of control, insults, and reperfusion. Error bars represent standard errors. Significance was determined using paired t-tests $\left(^{* *} \mathrm{p}<0.01\right.$ and ${ }^{\# \#} \mathrm{p}<0.01$, compared with before Hypo-Inf and hypoxia, respectively)

The input resistance of neurons reflects the ability of ions to penetrate the membrane and mainly relies on the gating of ion channels, including $\mathrm{HCN}, \mathrm{Na}_{\mathrm{V}}$, and $K_{V}$ channels $[13,14,49,50]$. We first excluded the $\mathrm{HCN}$ channel because $\mathrm{I}_{\mathrm{h}}$ changed in the opposite way to explain the input resistance alterations; that is, there 
was increased $I_{h}$ with increased input resistance and decreased $I_{h}$ with decreased input resistance [9]. Furthermore, the $I_{h}$ channel blocker zatebradine did not reverse the input resistance change by Hypo-Inf or reperfusion [9]. $\mathrm{Na}_{\mathrm{V}}$ is unlikely to be associated with input resistance because the input resistance was changed by Hypo-Inf and reperfusion in the same manner in the presence of TTX (Fig. 1). Therefore, in the present study, we focused on the role of $\mathrm{K}_{\mathrm{V}}$ channels in determining the input resistance during Hypo-Inf and reperfusion. $\mathrm{K}_{\mathrm{V}}$ channels are a prime candidate because the current density and gating kinetics are dynamically regulated by phosphorylation states [51-54], which are altered in response to ischemia [55-57].

In particular, the contribution of $\mathrm{I}_{\mathrm{A}}$ channels to excitability in hypoxia and reperfusion has attracted attention because of the dynamic regulation of their surface expression and dominant roles in determining excitability $[19,20]$. Indeed, numerous studies have suggested the direct involvement of $\mathrm{K}_{\mathrm{V}}$ channels in ischemia-induced activity changes but with no clear agreement [21-26, 2936]. Many of these conflicts could be attributed to the differential time points of the assessments during the course of hypoxia and reperfusion based on various methods of specimen preparation [24-29, 32-39]. The effects of hypoxia on $\mathrm{K}_{\mathrm{V}}$ channels were assessed by measuring the properties of $I_{A}$ and $I_{D R}$ many hours after posthypoxic reperfusion in some studies [21-26], whereas others examined them immediately after or during the hypoxic insult [29-31, 34, 35]. Potassium currents were measured from cultured neurons under chemical ATP depletion in some studies, while in other studies, the currents were measured from brain slices or in vivo with an insufficient oxygen supply. Furthermore, the concurrent effect of inflammation has been mostly ignored in the majority of in vitro studies $[22,29,34,35,54]$. To resolve this disagreement, we continuously monitored the changes in $\mathrm{K}_{\mathrm{V}}$ channel properties throughout hypoxia and reperfusion. Furthermore, we examined the combined (HypoInf) and independent (hypoxia or inflammation) effects of hypoxia and inflammation and reperfusion thereafter.

We found a significantly greater availability of $\mathrm{I}_{\mathrm{A}}$ channels during Hypo-Inf near the RMPs (Fig. 2) without alterations in the maximum $\mathrm{I}_{\mathrm{A}}$ density. The increased availability of $\mathrm{I}_{\mathrm{A}}$ was attributed to the less voltage-sensitive inactivation of $\mathrm{I}_{\mathrm{A}}$ channels during Hypo-Inf (Fig. 2b, c). Additionally, we found that the observed changes in $\mathrm{I}_{\mathrm{A}}$ channels by Hypo-Inf were caused by hypoxia.

To examine whether the absence of a change in the maximum $\mathrm{I}_{\mathrm{A}}$ density in Hypo-Inf could be explained by a combinatorial effect with inflammation, we examined $\mathrm{I}_{\mathrm{A}}$ with hypoxia or inflammation separately. However, no significant changes in $\mathrm{I}_{\mathrm{A}}$ density were found under conditions of hypoxia or inflammation alone. It must be noted that our analysis was focused on the acute effect of hypoxia or hypoxia with LPS-induced inflammation. The longer-term impact of inflammation, especially hypoxiaderived endogenous inflammation in vivo, should be examined in future studies.

We then tested whether changes in $\mathrm{I}_{\mathrm{DR}}$ density were involved in the altered input resistance produced by Hypo-Inf and reperfusion. Our results demonstrated that the $\mathrm{I}_{\mathrm{DR}}$ density changed in a manner that explained the input resistance changes with Hypo-Inf and reperfusion (Fig. 3). We could not identify a causal relationship between $I_{D R}$ and input resistance in the current study due to the lack of a method to selectively inhibit $\mathrm{I}_{\mathrm{DR}}$ density changes with Hypo-Inf. However, previous studies using a genetic mutation of $\mathrm{K}_{\mathrm{v}} 2$ channels, a major component of the $I_{D R}$ in hippocampal pyramidal neurons, have proven the role of $\mathrm{I}_{\mathrm{DR}}$ channels in determining input resistance $[58,59]$.

Interestingly, the effect of Hypo-Inf was not a simple sum of the two individual insults, hypoxia and inflammation. $\mathrm{I}_{\mathrm{DR}}$ density was initially increased by hypoxia alone but returned to the control levels in $\sim 10 \mathrm{~min}$, while inflammation alone had no direct effect on $\mathrm{I}_{\mathrm{DR}}$ density. The extended effect of inflammation may have been due to the mutually inducible interaction between hypoxia and inflammation. The complexity of the combined response by Hypo-Inf may be inherited from the complexity of reactive oxygen species (ROS)-mediated excitability regulation. Inflammation and hypoxia, as well as reperfusion, can induce the generation of ROS [60-62]. Enhanced excitatory synaptic transmission and excitability in various pathological conditions and pain transduction have been reported [63, 64]. In contrast, increased IDR reduced excitability and inhibited voltagegated $\mathrm{Ca} 2+$ channels were observed in cardiac neurons [65]. Long-term synaptic depression by internalization of glutamate receptors has been reported to mediate ROS signaling during Hypo-Inf [8]. The exact mechanism underlying the elongation of $\mathrm{I}_{\mathrm{DR}}$ density changes by inflammation under our experimental conditions needs to be further explored in future studies.

On the other hand, reperfusion-induced hyperexcitability correlated with a marked reduction in $\mathrm{I}_{\mathrm{DR}}$ density. The downregulation of $\mathrm{I}_{\mathrm{DR}}$ channels depolarizes the RMP and increases the input resistance, as observed in our previous study [9]. Our results were consistent with previous findings of posthypoxic reperfusion-induced epileptic neural activities in vitro and in vivo [21, 22, 66]. Supporting the idea that hyperexcitability can be driven by the regulation of $\mathrm{I}_{\mathrm{DR}}$ channels, animal models lacking $K_{\mathrm{V}} 2.1$ show enhanced susceptibility to epileptic neural activity and hyperactive behavior [67]. Moreover, 
mutations in the $\mathrm{K}_{\mathrm{V}} 2.1$ channel have been reported as genetic causes of epileptic encephalopathy in human patients $[59,68,69]$. Therefore, we concluded that the dynamic regulation of $\mathrm{I}_{\mathrm{DR}}$ density regulates the excitability of neurons during hypoxia and reperfusion.

The detailed molecular mechanism underlying the regulation of $\mathrm{I}_{\mathrm{DR}}$ density is beyond the scope of the current study, but the conductance control of $\mathrm{I}_{\mathrm{DR}}$ through distribution patterns of the channels has recently attracted attention. It has been observed that dispersed $\mathrm{K}_{\mathrm{v}} 2.1$ channels conduct potassium ions more efficiently than clustered $\mathrm{K}_{\mathrm{V}} 2.1$ channels [70, 71]. Clustering of the $\mathrm{K}_{\mathrm{V}} 2.1$ channel is regulated through activity-dependent phosphorylation by cyclin-dependent kinase 5 (Cdk5) [72]. Indeed, enhanced activity of Cdk 5 has been reported after hypoxia/ischemic injury $[73,74]$.

We next tested whether changes in $\mathrm{I}_{\mathrm{DR}}$ densities by Hypo-Inf and reperfusion were due to the altered voltage dependency of the channel activation. Previous studies observed that ischemia dephosphorylated $\mathrm{K}_{\mathrm{V}} 2.1$ channels through calcineurin and declustered them, consequently shifting the voltage-dependent activation of $\mathrm{I}_{\mathrm{DR}}$ channels toward the hyperpolarizing direction [34, 35]. However, we observed that Hypo-Inf, as well as hypoxia alone, induced a depolarizing shift regarding the activation of $I_{D R}$ channels, despite the enhanced $I_{D R}$ density (Fig. 4). The shifted activation curves of $\mathrm{I}_{\mathrm{DR}}$ by Hypo-Inf could be a result of compensation for the rapidly increased $I_{D R}$ density. This discrepancy can be explained by experimental differences. Previous studies examined $I_{D R}$ kinetic changes via chemical ATP depletion from cultured neurons and cortical slices [34, 35], whereas we assessed the effect of insufficient oxygen supply in hippocampal neurons in acutely prepared brain slices. Increased $I_{D R}$ density, despite the shifted activation during hypoxia, suggested that the number of $I_{D R}$ channels on the surface may have been actively regulated by the level of oxygen $[15,75,76]$.

In conclusion, we demonstrated that excitability altered by hypoxia and reperfusion can be attributed to input resistance changes through dynamic regulation of $\mathrm{K}_{\mathrm{V}}$ channels. Further work should examine changes in excitability in various brain regions and the dependence of these channels at the system level. Such research would directly evaluate the selective regulation of neuronal $\mathrm{K}_{\mathrm{V}}$ channels as a therapeutic or neuroprotective method to ameliorate the effects of hypoxia and reperfusion.

\section{Abbreviations}

AC: Adenylyl cyclase; ACSF: Artificial cerebrospinal fluid; AP: Action potential; ATP: Adenosine triphosphate; CAMP: Cyclic adenosine monophosphate; Cdk5: Cyclin-dependent kinase 5; CR3: Complement receptor 3; HCN: Hyperpolarization-activated cyclic nucleotide-gated cation; HIF: Hypoxia-inducible factor; Hypo-Inf: Hypoxia with inflammation; $I_{A}$ : A-type potassium current; $I_{D R}$ :
Delayed rectifier potassium current; $l_{h}$ : Hyperpolarization-activated current; $K_{V}$ channel: Voltage-gated potassium channel; LJP: Liquid junction potential; LPS: Lipopolysaccharide; $\mathrm{Na}_{V}$ channel: Voltage-gated sodium channel; NF-kB: Nuclear factor-kB; PKA: Protein kinase A; RMP: Resting membrane potential; ROS: Reactive oxygen species; SNARE: Soluble $N$-ethylmaleimide-sensitive factor attachment protein receptors; TLR4: Toll-like receptor 4; TTX: Tetrodotoxin; $V_{h}$ : Voltage half.

\section{Supplementary Information}

The online version contains supplementary material available at https://doi. org/10.1186/s13041-021-00857-9.

Additional file 1: Figure S1. The maximum density of IA before, during, and after Hypo-Inf. Error bars represent standard errors.

\section{Acknowledgements}

We thank the members of the Rah laboratory for their constructive discussion.

\section{Authors' contributions}

J-CR conceptualized the experiments and supervised the research. Y-SY performed electrophysiology and was a major contributor in writing the manuscript. J-CR edited the manuscript, and JC performed the statistical analysis. All authors read and approved the final manuscript.

\section{Funding}

This work was supported by the KBRI Research Program (21-BR-01-01 and 21-BR-03-01), DGIST R\&D program (21-IJRP-01), and research programs through the National Research Foundation (2017M3C7A1048086 and 2017M3A9G8084463) funded by the Ministry of Science and ICT.

\section{Availability of data and materials}

The data used in our study are available from the authors upon reasonable request.

\section{Declarations}

\section{Ethics approval and consent to participate}

All animal care and treatment protocols were approved by the Animal Care and Use Committee of the Korea Brain Research Institute (KBRI IACUC no. IACUC-18-00028).

\section{Consent for publication}

Not applicable.

\section{Competing interests}

The authors declare no competing interests.

\section{Author details}

${ }^{1}$ Korea Brain Research Institute, 61 Cheomdan-ro, Dong-gu, Daegu 41062, South Korea. ${ }^{2}$ Department of Brain \& Cognitive Sciences, Daegu Gyeongbuk Institute of Science and Technology, 333 Techno Jungang-daero, Dalseong-gun, Daegu 42988, South Korea.

Received: 13 July 2021 Accepted: 7 September 2021

Published online: 23 September 2021

\section{References}

1. Zhan X, Ander BP, Jickling G, Turner R, Stamova B, Xu H, et al. Brief focal cerebral ischemia that simulates transient ischemic attacks in humans regulates gene expression in rat peripheral blood. J Cereb Blood Flow Metab. 2010;30:110-8. https://doi.org/10.1038/jcbfm.2009.189.

2. Eltzschig HK, Carmeliet P. Hypoxia and inflammation. N Engl J Med. 2011;364:656-65. https://doi.org/10.1056/NEJMra0910283.

3. Eltzschig HK, Eckle T. Ischemia and reperfusion_from mechanism to translation. Nat Med. 2011;17:1391-401. 
4. Zlokovic BV. Neurovascular pathways to neurodegeneration in Alzheimer's disease and other disorders. Nat Rev Neurosci. 2011;12:723-38.

5. Taylor CT. Interdependent roles for hypoxia inducible factor and nuclear factor-KB in hypoxic inflammation. J Physiol. 2008;586:4055-9. https://doi. org/10.1113/jphysiol.2008.157669.

6. Gelderblom M, Leypoldt F, Steinbach K, Behrens D, Choe CU, Siler DA, et al. Temporal and spatial dynamics of cerebral immune cell accumulation in stroke. Stroke. 2009;40:1849-57. http://stroke.ahajournals.org.

7. Varatharaj A, Galea I. The blood-brain barrier in systemic inflammation. Brain Behav Immun. 2017;60:1-12.

8. Zhang J, Malik A, Choi HB, Ko RWY, Dissing-Olesen L, MacVicar BA. Microglial CR3 activation triggers long-term synaptic depression in the hippocampus via NADPH oxidase. Neuron. 2014;82:195-207. https://doi. org/10.1016/j.neuron.2014.01.043.

9. Yang YS, Son SJ, Choi JH, Rah JC. Synaptic transmission and excitability during hypoxia with inflammation and reoxygenation in hippocampal CA1 neurons. Neuropharmacology. 2018;138:20-31. https://doi.org/10. 1016/j.neuropharm.2018.05.011.

10. Camilo O, Goldstein LB. Seizures and epilepsy after ischemic stroke. Stroke. 2004:1769-75. http://ahajournals.org.

11. Jensen FE, Wang C, Stafstrom CE, Liu Z, Geary C, Stevens MC. Acute and chronic increases in excitability in rat hippocampal slices after perinatal hypoxia in vivo. J Neurophysiol. 1998;79:73-81.

12. Myint PK, Staufenberg EFA, Sabanathan K. Post-stroke seizure and poststroke epilepsy. Postgrad Med J. 2006;971:568-72.

13. Kase $D$, Imoto $K$. The role of HCN channels on membrane excitability in the nervous system. J Signal Transduct. 2012;2012:11.

14. Benarroch EE. HCN channels: function and clinical implications. Neurology. 2013;80:304-10. https://n.neurology.org/content/80/3/304.

15. Shah NH, Aizenman E. Voltage-gated potassium channels at the crossroads of neuronal function, ischemic tolerance, and neurodegeneration. Transl Stroke Res. 2014;5:38-58.

16. Yeh CY, Bulas AM, Moutal A, Saloman JL, Hartnett KA, Anderson CT, et al. Targeting a potassium channel/syntaxin interaction ameliorates cell death in ischemic stroke. J Neurosci. 2017:37:5648-58.

17. Schulie AJ, Yeh CY, Orang BN, Pa OJ, Hopkin MP, Moutal A, et al. Targeted disruption of Kv2.1-VAPA association provides neuroprotection against ischemic stroke in mice by declustering Kv2.1 channels. Sci Adv. 2020;6:eaaz8110.

18. Smart SL, Lopantsev V, Zhang CL, Robbins CA, Wang H, Chiu SY, et al. Deletion of the $K(v) 1.1$ potassium channel causes epilepsy in mice. Neuron. 1998;20:809-19.

19. Kim J, Wei DS, Hoffman DA. Kv4 potassium channel subunits control action potential repolarization and frequency-dependent broadening in rat hippocampal CA1 pyramidal neurones. J Physiol. 2005;569:41-57.

20. Hammond RS, Lin L, Sidorov MS, Wikenheiser AM, Hoffman DA. Protein kinase a mediates activity-dependent Kv4.2 channel trafficking. J Neurosci. 2008;28:7513-9.

21. Peng BW, Justice JA, He XH, Sanchez RM. Decreased A-currents in hippocampal dentate granule cells after seizure-inducing hypoxia in the immature rat. Epilepsia. 2013:54:1223-31.

22. Liu YQ, Huang WX, Sanchez RM, Min JW, Hu JJ, He XH, et al. Regulation of Kv4.2 a-type potassium channels in HEK-293 cells by hypoxia. Front Cell Neurosci. 2014:8:1-10

23. Accorsi-Mendonça D, EL Almado C, Bonagamba LG, Castania JA, Moraes DJ, Machado BH. Enhanced firing in NTS induced by short-term sustained hypoxia is modulated by glia-neuron interaction. J Neurosci. 2015:35:6903-17.

24. Chi XX, Xu ZC. Differential changes of potassium currents in CA1 pyramidal neurons after transient forebrain ischemia. J Neurophysiol. 2000;84:2834-43.

25. Zou B, Li Y, Deng P, Xu ZC. Alterations of potassium currents in ischemiavulnerable and ischemia-resistant neurons in the hippocampus after ischemia. Brain Res. 2005;1033:78-89.

26. Deng P, Pang ZP, Lei Z, Shikano S, Xiong Q, Harvey BK, et al. Up-regulation of A-type potassium currents protects neurons against cerebral ischemia. J Cereb Blood Flow Metab. 2011;31:1823-35.

27. Mezghani-Abdelmoula S, Chevalier S, Lesouhaitier O, Orange N, Feuilloley MGJ, Cazin L. Pseudomonas fluorescens lipopolysaccharide inhibits both delayed rectifier and transient A-type $\mathrm{K}+$ channels of cultured rat cerebellar granule neurons. Brain Res. 2003;983:185-92.

28. Hu D, Liu J, Keblesh J, Xiong H. Involvement of the 4-aminopyridinesensitive transient A-type $\mathrm{K}+$ current in macrophage-induced neuronal injury. Eur J Neurosci. 2010;31:214-22.

29. Gebhardt C, Heinemann U. Anoxic decrease in potassium outward currents of hippocampal cultured neurons in absence and presence of dithionite. Brain Res. 1999;837:270-6.

30. Krnjevic K, Leblond J. Changes in membrane currents of hippocampal neurons evoked by brief anoxia. J Neurophysiol. 1989;62:15-30. https:// doi.org/10.1152/jn.1989.62.1.15.

31. Cummins TR, Donnelly DF, Haddad GG. Effect of metabolic inhibition on the excitability of isolated hippocampal CA1 neurons: developmental aspects. J Neurophysiol. 1991;66:1471-82. https://doi.org/10.1152/jn. 1991.66.5.1471.

32. Deng P, Pang ZP, Zhang Y, Xu ZC. Increase of delayed rectifier potassium currents in large aspiny neurons in the neostriatum following transient forebrain ischemia. Neuroscience. 2005;131:135-46.

33. Wu KW, Yang P, Li SS, Liu CW, Sun FY. VEGF attenuated increase of outward delayed-rectifier potassium currents in hippocampal neurons induced by focal ischemia via PI3-K pathway. Neuroscience. 2015:298:94-101.

34. Misonou H, Mohapatra DP, Menegola M, Trimmer JS. Calcium- and metabolic state-dependent modulation of the voltage-dependent Kv2.1 channel regulates neuronal excitability in response to ischemia. J Neurosci. 2005;25:11184-93.

35. Misonou H, Thompson SM, Cai X. Dynamic regulation of the Kv2.1 voltage-gated potassium channel during brain ischemia through neuroglial interaction. J Neurosci. 2008;28:8529-38.

36. Hu D, Jianuo L, Huangui X. Enhancement of neuronal outward delayed rectifier K+ current by human monocyte-derived macrophages. Glia. 2009;57:1492-500.

37. Shaw K, Bell L, Boyd K, Grijseels DM, Clarke D, Bonnar O, et al. Neurovascular coupling and oxygenation are decreased in hippocampus compared to neocortex because of microvascular differences. Nat Commun. 2021;12:1-16.

38. Lee CH, Yoo KY, Choi JH, Park OK, Hwang IK, Kim SK, et al. Neuronal damage is much delayed and microgliosis is more severe in the aged hippocampus induced by transient cerebral ischemia compared to the adult hippocampus. J Neurol Sci. 2010;294:1-6.

39. Nikonenko AG, Radenovic L, Andjus PR, Skibo GG. Structural features of ischemic damage in the hippocampus. Anat Rec (Hoboken). 2009;292:1914-21.

40. Hossmann K-A. The hypoxic brain. Boston: Springer; 1999. p. 155-69. https://doi.org/10.1007/978-1-4615-4711-2_14.

41. Ka J. The pathology of ischemic-vascular dementia: an update. J Neurol Sci. 2002;203-204:153-7.

42. Jellinger KA. The enigma of vascular cognitive disorder and vascular dementia. Acta Neuropathol. 2007;113:349-88. https://doi.org/10.1007/ s00401-006-0185-2.

43. Zola-Morgan S, Squire LR, Rempel NL, Glower RP, Amara DG. Enduring memory impairment in monkeys after Ischemic damage to the hippocampus. J Neurosci. 1992;12:2582-98.

44. Bachevalier J, Meunier M. Cerebral ischemia: are the memory deficits associated with hippocampal cell loss? Hippocampus. 1996;6:553-60.

45. Rossi DJ, Oshima T, Attwell D. Glutamate release in severe brain ischaemia is mainly by reversed uptake. Nature. 2000;403:316-21.

46. Rossi DJ, Brady JD, Mohr C. Astrocyte metabolism and signaling during brain ischemia. Nat Neurosci. 2007:10:1377-86.

47. Pei Z, Pang H, Qian L, Yang S, Wang T, Zhang W, et al. MAC1 mediates LPS-induced production of superoxide by microglia: the role of pattern recognition receptors in dopaminergic neurotoxicity. Glia. 2007;55:136273. https://doi.org/10.1002/glia.20545.

48. Mulkey R, Herron C, Malenka R. An essential role for protein phosphatases in hippocampal long-term depression. Science (80-). 1993;261:1051-5.

49. Ceballos CC, Roque AC, Leão RM. The role of negative conductances in neuronal subthreshold properties and synaptic integration. Biophys Rev. 2017:9:827-34 
50. Cameron WE, Núnẽz-Abades PA, Kerman IA, Hodgson TM. Role of potassium conductances in determining input resistance of developing brain stem motoneurons. J Neurophysiol. 2000;84:2330-9.

51. Norris AJ, Foeger NC, Nerbonne JM. Neuronal voltage-gated K+ $(\mathrm{Kv})$ channels function in macromolecular complexes. Neurosci Lett. 2010;486:73-7.

52. Cerda O, Trimmer JS. Analysis and functional implications of phosphorylation of neuronal voltage-gated potassium channels. Neurosci Lett. 2010;486:60-7.

53. Jonas EA, Kaczmarek LK. Regulation of potassium channels by protein kinases. Curr Opin Neurobiol. 1996;6:318-23.

54. Qiu MH, Zhang R, Sun FY. Enhancement of ischemia-induced tyrosine phosphorylation of Kv1.2 by vascular endothelial growth factor via activation of phosphatidylinositol 3-kinase. J Neurochem. 2003;87:1509-17.

55. Tanaka K. Alteration of second messengers during acute cerebral ischemia-Adenylate cyclase, cyclic AMP-dependent protein kinase, and cyclic AMP response element binding protein. Prog Neurobiol. 2001;65:173-207.

56. Guan R, LV J, Xiao F, Tu Y, Xie Y, Li L. Potential role of the CAMP/PKA/CREB signalling pathway in hypoxic preconditioning and effect on propofolinduced neurotoxicity in the hippocampus of neonatal rats. Mol Med Rep. 2019;20:1837-45. https://doi.org/10.3892/mmr.2019.10397.

57. Gozal E, Metz CJ, Dematteis M, Sachleben LR, Schurr A, Rane MJ. PKA activity exacerbates hypoxia-induced ROS formation and hypoxic injury in PC-12 cells. Toxicol Lett. 2017;279:107-14.

58. Malin SA, Nerbonne JM. Delayed rectifier K+ currents, IK, are encoded by Kv2 a-subunits and regulate tonic firing in mammalian sympathetic neurons. J Neurosci. 2002;22:10094-105.

59. Saitsu H, Akita T, Tohyama J, Goldberg-Stern H, Kobayashi Y, Cohen R, et al De novo KCNB1 mutations in infantile epilepsy inhibit repetitive neuronal firing. Sci Rep. 2015;5:1-14. www.uniprot.org/uniprot/.

60. Chen R, Lai UH, Zhu L, Singh A, Ahmed M, Forsyth NR. Reactive oxygen species formation in the brain at different oxygen levels: the role of hypoxia inducible factors. Front Cell Dev Biol. 2018;6:132.

61. Solleiro-Villavicencio H, Rivas-Arancibia S. Effect of chronic oxidative stress on neuroinflammatory response mediated by CD4+T cells in neurodegenerative diseases. Front Cell Neurosci. 2018;12:114.

62. Chouchani ET, Pell VR, Gaude E, Aksentijević D, Sundier SY, Robb EL, et al. Ischaemic accumulation of succinate controls reperfusion injury through mitochondrial ROS. Nature. 2014;515:431-5.

63. Hi L, Br P, Sw C. Reactive oxygen species increase neuronal excitability via activation of nonspecific cation channel in rat medullary dorsal horn neurons. Korean J Physiol Pharmacol. 2017;21:371-6.

64. Li Z, Ji G, Neugebauer V. Mitochondrial reactive oxygen species are activated by mGluR5 through IP3 and activate ERK and PKA to increase excitability of amygdala neurons and pain behavior. J Neurosci. 2011;31:1114-27.

65. Whyte KA, Hogg RC, Dyavanapalli J, Harper AA, Adams DJ. Reactive oxygen species modulate neuronal excitability in rat intrinsic cardiac ganglia. Auton Neurosci. 2009;150:45-52.

66. Rodriguez-Alvarez N, Jimenez-Mateos EM, Dunleavy M, Waddington JL, Boylan GB, Henshall DC. Effects of hypoxia-induced neonatal seizures on acute hippocampal injury and later-life seizure susceptibility and anxietyrelated behavior in mice. Neurobiol Dis. 2015;83:100-14.

67. Speca DJ, Ogata G, Mandikian D, Bishop HI, Wiler SW, Eum K, et al. Deletion of the Kv2.1 delayed rectifier potassium channel leads to neuronal and behavioral hyperexcitability. Genes Brain Behav. 2014;13:394-408.

68. Kang SK, Vanoye CG, Misra SN, Echevarria DM, Calhoun JD, O'Connor JB, et al. Spectrum of KV2.1 dysfunction in KCNB1-associated neurodevelopmental disorders. Ann Neurol. 2019;86:899-912.

69. Torkamani A, Bersell K, Jorge BS, Bjork RL, Friedman JR, Bloss CS, et al. De novo KCNB1 mutations in epileptic encephalopathy. Ann Neurol. 2014;76:529-40.

70. Fox PD, Loftus RJ, Tamkun MM. Regulation of Kv2.1 K+ conductance by cell surface channel density. J Neurosci. 2013;33:1259-70.

71. O'Connell KMS, Loftus R, Tamkun MM. Localization-dependent activity of the Kv2.1 delayed-rectifier K + channel. Proc Natl Acad Sci USA. 2010;107:12351-6. https://doi.org/10.1073/pnas.1003028107.

72. Cerda O, Trimmer JS. Activity-dependent phosphorylation of neuronal Kv2.1 potassium channels by CDK5. J Biol Chem. 2011;286:28738-48.

73. Hayashi T, Warita H, Abe K, Itoyama Y. Expression of cyclin-dependent kinase 5 and its activator p35 in rat brain after middle cerebral artery occlusion. Neurosci Lett. 1999;265:37-40.

74. Tan X, Chen Y, Li J, Li X, Miao Z, Xin N, et al. The inhibition of Cdk5 activity after hypoxia/ischemia injury reduces infarct size and promotes functional recovery in neonatal rats. Neuroscience. 2015;290:552-60.

75. Duménieu M, Oulé M, Kreutz MR, Lopez-Rojas J. The segregated expression of voltage-gated potassium and sodium channels in neuronal membranes: functional implications and regulatory mechanisms. Front Cell Neurosci. 2017;11:115.

76. Bachmann M, Li W, Edwards MJ, Ahmad SA, Patel S, Szabo I, et al. Voltagegated potassium channels as regulators of cell death. Front Cell Dev Biol. 2020;8:1571.

\section{Publisher's Note}

Springer Nature remains neutral with regard to jurisdictional claims in published maps and institutional affiliations.
Ready to submit your research? Choose BMC and benefit from:

- fast, convenient online submission

- thorough peer review by experienced researchers in your field

- rapid publication on acceptance

- support for research data, including large and complex data types

- gold Open Access which fosters wider collaboration and increased citations

- maximum visibility for your research: over $100 \mathrm{M}$ website views per year

At BMC, research is always in progress.

Learn more biomedcentral.com/submissions 